\title{
PHYSIOLOGICAL RESPONSES OF ALFALFA SEEDLINGS TO FREEZE-THAW, NaCl AND $\mathrm{Na}_{2} \mathrm{SO}_{4} \mathrm{STRESS}$
}

\author{
BAO, G. ${ }^{1 *}-\mathrm{QU}, \mathrm{Y} .{ }^{1}-\mathrm{YAN}, \mathrm{B}^{2}-\mathrm{BIAN} \mathrm{W} .{ }^{1}-\mathrm{CHEN}, \mathrm{W} .{ }^{1}-\mathrm{LI}, \mathrm{Y} .{ }^{1}-\mathrm{CUI}, \mathrm{X} .{ }^{3}$ \\ ${ }^{1}$ Key Laboratory of Groundwater Resources and Environment (Jilin University), Ministry of \\ Education, Changchun 130012, China \\ ${ }^{2}$ Environmental Monitoring Center Station of Jilin Province, Changchun 130011, China \\ ${ }^{3}$ Jilin University School of Law, Jilin University, Changchun 130012, China \\ *Corresponding author \\ e-mail: baogz@jlu.edu.cn; fax: +86-0431-8850-2606 \\ (Received 23 ${ }^{\text {rd }}$ Dec 2019; accepted 23 ${ }^{\text {rd }}$ Mar 2020)
}

\begin{abstract}
NaCl}$ and $\mathrm{Na}_{2} \mathrm{SO}_{4}$, two common neutral salts, often cause salt stress in saline-alkaline grassland in Northeast China. The purpose of this experiment is to reveal the effects of the combined stress of these two neutral salts and the freeze-thaw cycles of spring and autumn on the physiological and ecological characteristics of alfalfa seedlings. By measuring the soluble protein, soluble sugar, proline, malondialdehyde (MDA) content, Peroxidase activity (POD) and Superoxide dismutase (SOD) activity of alfalfa seedlings treated with two types of salt solution $\left(\mathrm{NaCl}\right.$ and $\left.\mathrm{Na}_{2} \mathrm{SO}_{4}\right)$ in a freeze-thaw cycle, the physiological and ecological responses of alfalfa seedlings under combined stress were investigated, and the differences in the stress of plant seedlings between the two salt solutions were compared. Stress damage mainly resulted from low temperature, penetration and ionic toxicity. A series of tolerance mechanisms were observed in the plants to cope with the stress. Under the compound stress, plant damage was exacerbated. The highlight of this study is that two different types of salinity had ion specificity for the toxic effects of alfalfa, and the toxic effects of $\mathrm{Cl}^{-}$were the main factors, not $\mathrm{Na}^{+}$or $\mathrm{SO}_{4}{ }^{2-}$. Alfalfa exposed to $\mathrm{SO}_{4}{ }^{2-}$ salt could cope with salt stress relatively better.
\end{abstract}

Keywords: alfalfa, freeze-thaw, tolerance mechanisms, salinity, combined stress

\section{Introduction}

The northern part of China is cold in winter, and pasture survives winter difficultly. In the spring and autumn, pastures are often affected by cold currents, and are subjected to freeze-thaw cycles, resulting in poor growth and low yield, which reduce the utilization value of pasture. Therefore, temperature is one of the important limiting factors for the use value of pasture (Stushnoff and Junttila, 1986). At the same time, soil salinization in Northeast China is serious, and salt is one of the main limiting factors for improving crop growth and productivity (Flowers, 2004; Kanmani et al., 2017). The main consequences of plant exposed to salt stress are water deficits and excess ions, leading to several morphological and physiological changes (Greenway and Munns, 2003; Türkan and Demiral, 2009). High concentrations of ions in the external solution may be absorbed at a high rate, which may result in excessive accumulation in plant tissues. These ions may affect the membrane's ability to selectively permeate and interfere with the absorption of other ions, thereby altering the amount of a series of elements in the tissue ( $\mathrm{Hu}$ and Schmidhalter, 2005). Therefore, in the face of soil salinization, breeding salt-tolerant varieties and direct use of saline-alkali land are more cost-effective solutions for improving and utilizing saline-alkali land. 
According to the survey, alfalfa (Medicago sativa L.) is one of the most common saline-alkali land forage in northeastern China and high latitudes. As a high-quality forage cultivated artificially, alfalfa has strong cold and salt resistance. It is a common plant for the improvement of saline-alkali land in Northeast China, and also a test material commonly used in the study of cold tolerance and salt-tolerance of plants. Alfalfa is sensitive to salt at seedling stage, and the seedlings have a consistent response to salt throughout the growth stage, and salt selection is most suitable at this stage (AlKhatib et al., 1994, 1987).

At present, researches on the cold tolerance and salt tolerance of seedlings mainly focus on single factor stress conditions, such as salt tolerance physiology (Akandi et al., 2017), cold resistance and survival rate (Skinner and Bellinger, 2017), and drought resistance (Pompeiano et al., 2016), and those on the physiological laws of compound stress are rare. In the early spring and late autumn of the cold regions of Northeast China, freeze-thaw and salt stresses are the most common, and the salt types in the saline-alkaline grasslands in Northeast China are mainly alkaline salts, and some are neutral salts. The main components of neutral salts are sodium salts, including sodium chloride and sodium sulfate. Most studies on the salt tolerance of plant species are based on experiments where $\mathrm{NaCl}$ is the main salt, and the symptoms of injury are usually attributed to the toxicity of $\mathrm{Na}^{+}$and $\mathrm{Cl}^{-}$. Relatively few studies (Nguyen et al., 2006; Renault et al., 2001; Rogers et al., 1998) focus on the effects of $\mathrm{Na}_{2} \mathrm{SO}_{4}$ on plant growth and physiology. Therefore, this study used Dongmu-1 alfalfa as the experimental object to study the changes of soluble protein, malondialdehyde (MDA), soluble sugar, proline content and SOD and POD activity in the alfalfa seedlings under the combined stress of freeze-thaw and salt $\left(\mathrm{NaCl}\right.$ or $\left.\mathrm{Na}_{2} \mathrm{SO}_{4}\right)$. The physiological response mechanism of cold resistance and salt tolerance in alfalfa seedlings was revealed.

\section{Materials and methods}

\section{Experimental materials}

In this study, the indoor culture experiment method was adopted, and the test seedlings were Dongmu-1 alfalfa. The alfalfa seeds with uniform grain size and no pests were picked carefully, disinfected with $0.1 \% \mathrm{KMnO}_{4}$ for $10 \mathrm{~min}$, rinsed with double distilled water, and then cultured in several culture dishes with a diameter of $100 \mathrm{~mm}$. Two layers of filter paper were laid in each dish, and around 100 seeds were placed evenly place, immersed appropriate amount of water. The culture dishes were placed in a constant temperature incubator for growth and germination, and the light collection period was $12 \mathrm{~h}$, with illumination time at $25^{\circ} \mathrm{C}$ and non-lighting time at $15^{\circ} \mathrm{C}$. During the germination period, appropriate amount of water was added three times a day. When the third cotyledon grew, the plants with the same growth were selected for stress treatment.

\section{Experimental methods}

The treatment solvents selected were $\mathrm{NaCl}$ and $\mathrm{Na}_{2} \mathrm{SO}_{4}$, and according to the growth condition of the seedling, the concentration of each salt was $100 \mathrm{mmol} / \mathrm{L}$. After the treatment, the plants were cultured for two days. The salt-treated experimental groups and the control group (CK) were divided into two groups respectively. One was subjected to freeze-thaw stress, and the other was cultured at room temperature. The 
temperature of the freeze-thaw cycle was controlled by an ultra-low temperature alternating test chamber, and the temperature was set to $10^{\circ} \mathrm{C}, 5^{\circ} \mathrm{C}, 0^{\circ} \mathrm{C},-3{ }^{\circ} \mathrm{C}$ (Deng et al., 2005) have found that $-3{ }^{\circ} \mathrm{C}$ is the lowest temperature for alfalfa seedlings to withstand low temperature), $0{ }^{\circ} \mathrm{C}, 5^{\circ} \mathrm{C}$ and $10^{\circ} \mathrm{C}$, with an interval of two hours. Treated groups and control groups were sampled at each temperature. Three sets of parallel samples were taken from each group, and the relevant indicators were determined after sampling.

CK group is blank control group without salt solution and freeze-thaw cycle; FT group is only treated by a freeze-thaw cycle; $\mathrm{FT}+\mathrm{NaCl}$ group is the one with $\mathrm{NaCl}$ solution and a freeze-thaw cycle; $\mathrm{FT}+\mathrm{Na}_{2} \mathrm{SO}_{4}$ group is the one added $\mathrm{Na}_{2} \mathrm{SO}_{4}$ solution and subjected to a freeze-thaw cycle. T1-T7 correspond to $10^{\circ} \mathrm{C}, 5^{\circ} \mathrm{C}, 0{ }^{\circ} \mathrm{C},-3{ }^{\circ} \mathrm{C}, 0{ }^{\circ} \mathrm{C}$, $5^{\circ} \mathrm{C}, 10^{\circ} \mathrm{C}$, respectively.

Samples were grinded to homogenate with $5 \mathrm{ml}$ distilled water $(5 \mathrm{ml}$ of $10 \%$ trichloroacetic acid solution used for MDA and soluble sugar content, and $5 \mathrm{ml}$ of $3 \%$ sulfosalicylic acid solution used for proline content instead) in a mortar. After centrifugation for $10 \mathrm{~min}(3000 \mathrm{r} / \mathrm{min})$, the supernatant was picked for measurement (protein: G250-Coomassie brilliant blue method; MDA and soluble sugar: thiobarbituric acid method; proline: acid ninhydrin colorimetry). The SOD and POD activity was determined by SOD (superoxide dismutase) and POD (peroxidase) kits (Nanjing Jiancheng Bioengineering Institute), respectively.

\section{Data analysis}

The experimental data were graphed with Microsoft (Redmond, USA) Excel, and statistical analysis was performed with SPSS 16.0 statistical software (IBM SPSS Statistics, Chicago, USA) using single factor variance analysis (one-way analysis of variance) and multiple comparisons with least significant difference (LSD). The significance level was at 0.05 , the experiments were repeated five times, and all of the results are presented as mean $\pm \mathrm{SE}$.

\section{Results and discussion}

\section{Change in osmotic adjustment substance content}

Soluble protein, soluble sugar, and proline are common osmotic adjustment substances in plants, and their levels can reflect the degree of stress on plants.

As can be seen from Figure 1, the three treatment groups exhibited substantially the same trend throughout the freeze-thaw cycle. At the initial stage of temperature decrease, the protein content increased slightly, mainly due to the small temperature stress, and the plant stress response rapidly regulated the metabolism and increased protein content. At the lowest temperature $\left(-3^{\circ} \mathrm{C}\right)$, the degree of stress reached the maximum and the protein content went up significantly, indicating that alfalfa seedlings were most sensitive at $-3{ }^{\circ} \mathrm{C}$. The low temperature caused plants to produce a stressresistant reaction, and the related genes were overexpressed (Guy, 1990; Hannah et al., 2005; Hahn and Walbot, 1989; Seppänen et al., 1998), and cold-resistant proteins were synthesized, resulting in an increase in the total amount of protein. This is consistent with the conclusion of (Weiser, 1970) who proposed that low temperature could induce plant protein production. When the temperature gradually rose, the soluble protein content of the three treatment groups decreased (Bian et al., 2018). However, the 
difference was that the FT group and the FT $+\mathrm{Na}_{2} \mathrm{SO}_{4}$ group decreased significantly, while the $\mathrm{FT}+\mathrm{NaCl}$ group decreased slowly, indicating that as the temperature rose, the low temperature stress on the plants was gradually reduced, and the excess soluble proteins were catabolized progressively. The addition of salt could destroy plant cells, causing cells to rupture in high salinity solutions, which is an irreversible process. $\mathrm{Cl}^{-}$ had strong destructive power to cells, and even if the temperature rose, a large amount of soluble proteins could not be metabolized, while the destructive power of $\mathrm{SO}_{4}{ }^{2-}$ was relatively weaker, and soluble proteins in $\mathrm{FT}+\mathrm{Na}_{2} \mathrm{SO}_{4}$ group were partially metabolized.

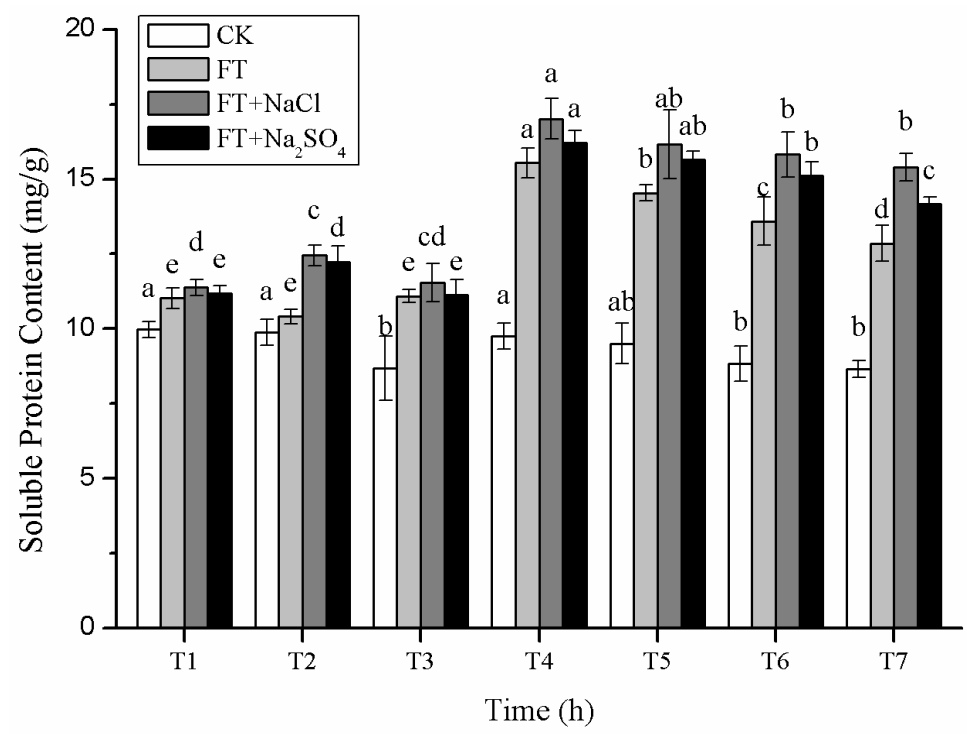

Figure 1. Effect of freezing-thawing cycle and two neutral salts on the content of soluble protein

Studies have shown that freeze-thaw cycles can change the accumulation of lipids and carbohydrates in plants (Skinner et al., 2014). A large amount of ions would be accumulated in the salt-treated plants and are sequestered in the vacuole, and nonabsorbable compounds, such as sugar (Briens and Larher, 2010; Matoh and Matsushita, 2010) and leaf proline (Pagter et al., 2009), may act as compatible organic solutes to balance cytoplasmic osmotic pressure (James et al., 2002; Volkmar et al., 1998). As can be seen from Figures 2 and 3, as the temperature descended, the soluble sugar and proline contents gradually ascended, reaching the highest at the lowest temperature ($3{ }^{\circ} \mathrm{C}$ ) (Bao et al., 2017). Cooling allowed the seedlings to actively accumulate soluble sugar and proline, maintain the osmotic potential inside and outside the cells, ensure the normal structure of the cell membrane, reduce the freezing point of the cells, increase the hydration of the cells, giving rise to enhancement of water retention capacity and avoidance of probiotic damage to dehydration at low temperature. The soluble sugar and proline contents decreased slightly as the temperature went up in the late stage of the experiment, but they were still high. There was almost no significant difference between the groups $(P>0.05)$. The cell thawing process was slow, and sustained low temperature damage resulted in accumulation of soluble sugar and proline used to reduce coercive damage in plants. Moreover, the changes of the index of each group were roughly as follows: $\mathrm{FT}+\mathrm{NaCl}$ group $>\mathrm{FT}+\mathrm{Na}_{2} \mathrm{SO}_{4}$ group $>\mathrm{FT}$ group $>\mathrm{CK}$ 
group, indicating that compound stress was severer than single stress, and the increased osmotic adjustment substance was both used to maintain the osmotic potential of the cells and to resist the damage caused by low temperature. Therefore, the content of osmotic adjustment substances in the complex stress group was significantly higher than that in the freeze-thaw group. However, if the increase of osmotic adjustment substances was only related to the external environmental salt concentration, it was independent of the salinity type. It should have shown that the FT $+\mathrm{Na}_{2} \mathrm{SO}_{4}$ group had more osmotic adjustment substances, since $\mathrm{Na}_{2} \mathrm{SO}_{4}$ in the equimolar two salt solutions should contain a higher concentration of $\mathrm{Na}^{+}$. Therefore, the difference between the two salt-treated groups was caused by the difference between $\mathrm{Cl}^{-}$and $\mathrm{SO}_{4}{ }^{2-}$ ions, and the alfalfa seedlings were more sensitive to $\mathrm{Cl}^{-}$.

\section{Changes in biofilm damage}

MDA is a product of membrane lipid peroxidation in plant cells. Studies (Bailly et al., 1996; Greenway and Munns, 2003) have shown that degree of could be reflected in the content of MDA. It can be seen from Figure 4 that there was no significant change in MDA content in the CK group $(P>0.05)$, and the MDA changes in the freeze-thaw group and the two compound stress groups were the same. With the decrease of temperature, the MDA content increased significantly, and the three groups all peaked at T4 $\left(-3{ }^{\circ} \mathrm{C}\right), 18.30 \mu \mathrm{mol} \cdot \mathrm{L}^{-1}, 23.75 \mu \mathrm{mol} \cdot \mathrm{L}^{-1}, 21.55 \mu \mathrm{mol} \cdot \mathrm{L}^{-1}$, respectively. Compared with T1, T2 and T3, there were significant differences $(P>0.05)$, indicating that the lower the temperature was, the higher the MDA content produced in the alfalfa seedlings. With the increase of temperature, the MDA content of the three treatment groups decreased slightly but remained high. There was almost no significant difference between the groups $(P>0.05)$. This may be due to the membrane lipid peroxidation caused by low temperature and resulted in the accumulation of MDA. The continuous low temperature caused the cells to thaw slowly, and although the temperature gradually went up, plants were still subjected to cold stress, showing a slight decline and followed a trend to be stable.

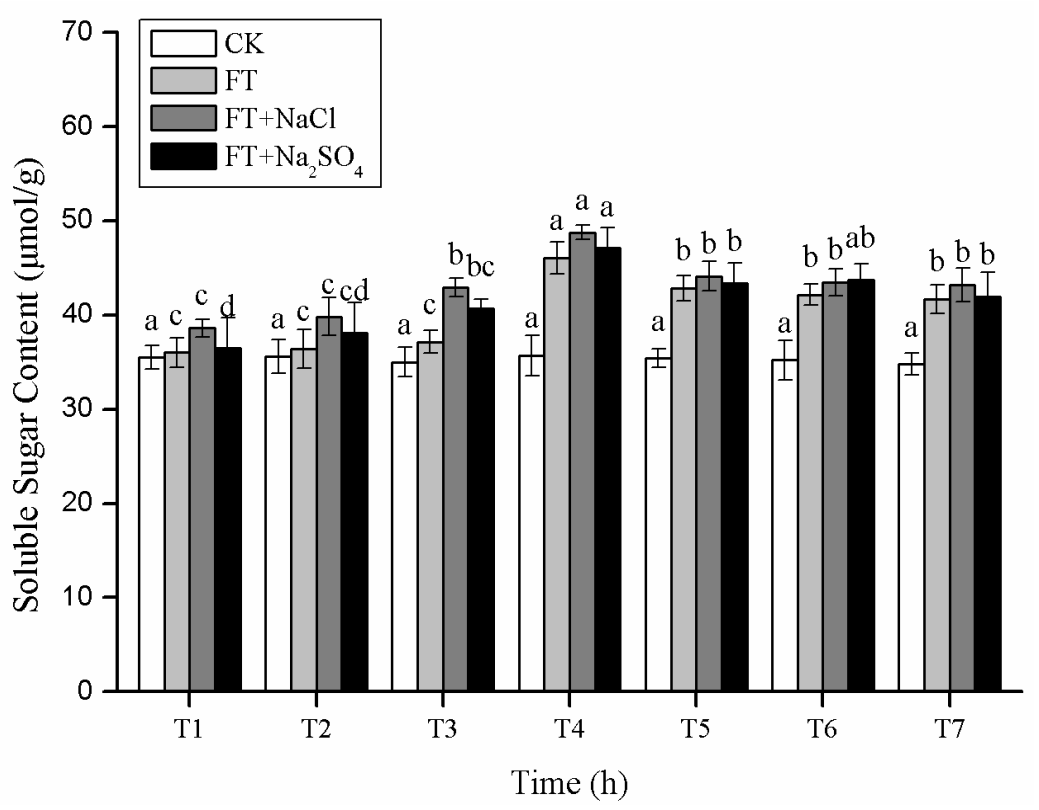

Figure 2. Effect of freezing-thawing cycle and two neutral salts on the content of soluble sugar 


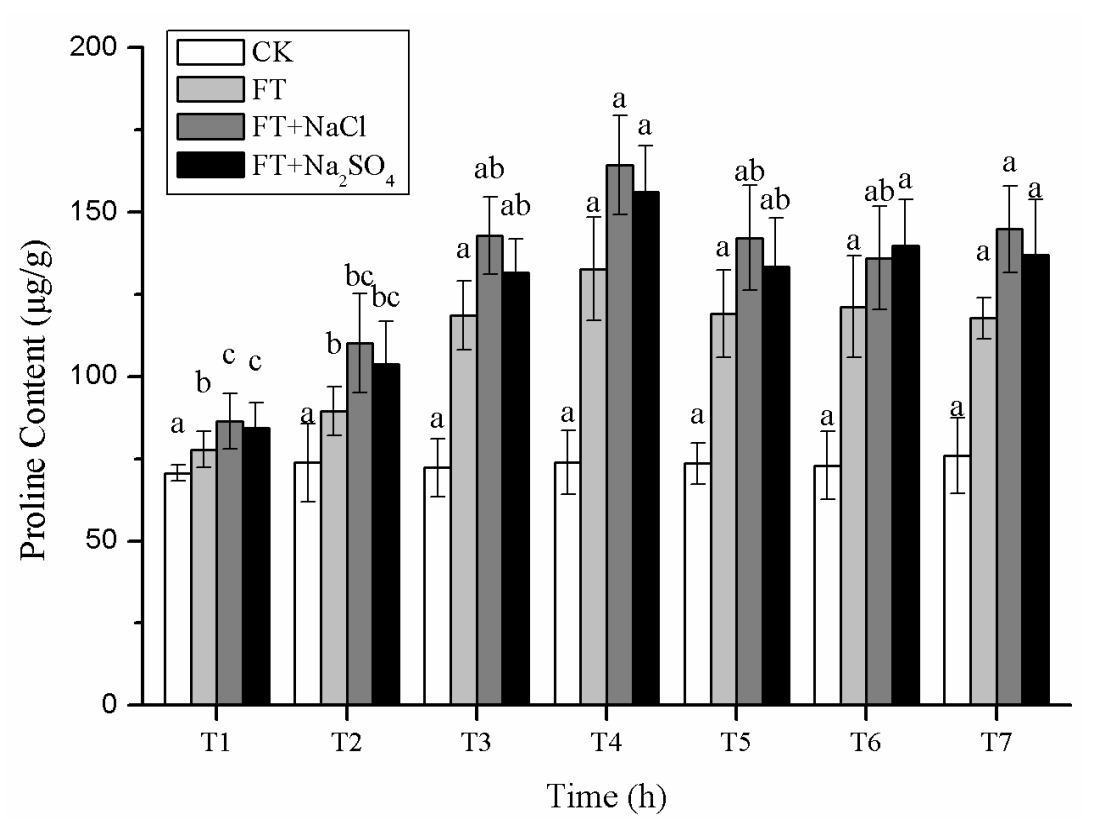

Figure 3. Effect of freezing-thawing cycle and two neutral salts on the content of proline

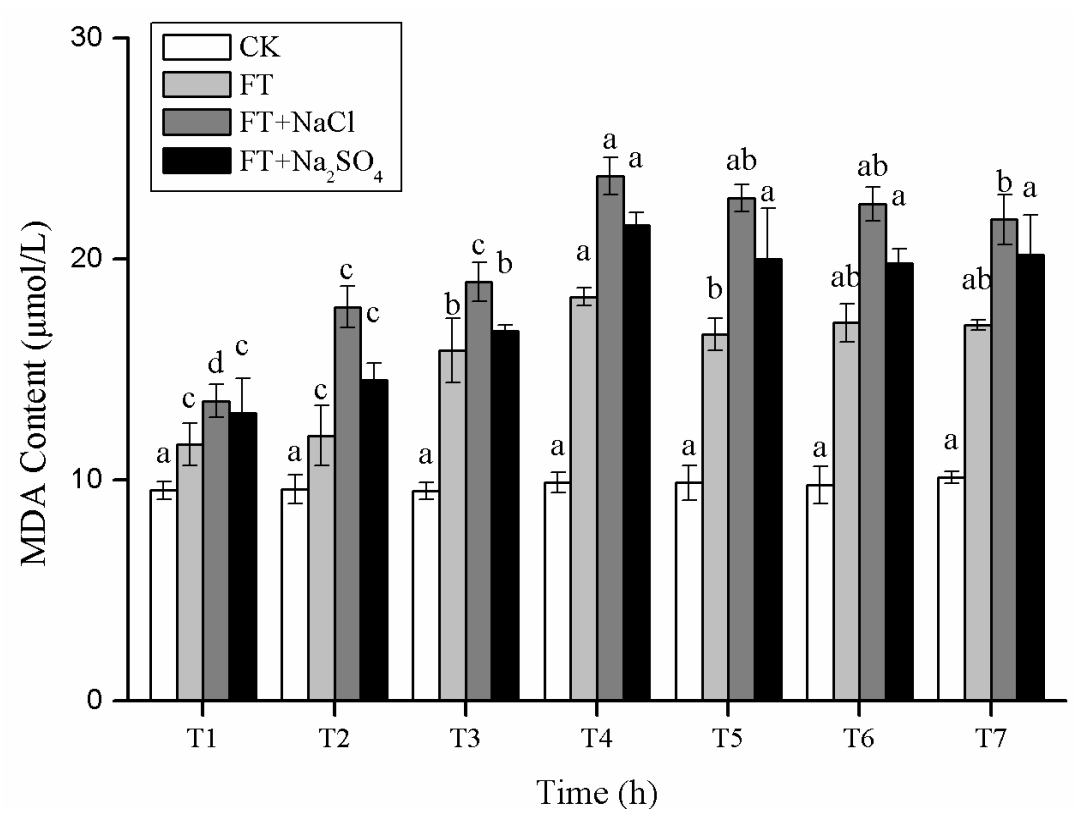

Figure 4. Effect of freezing-thawing cycle and two neutral salts on the content of MDA

In the longitudinal comparison, the MDA content of the three treatment groups was higher than that of the CK group, indicating that the alfalfa seedlings started to be subjected to cold stress at $10{ }^{\circ} \mathrm{C}$. The combined stress of freeze-thaw and $\mathrm{NaCl}$ resulted in the highest MDA content in the seedlings, 4.28-13.84\% more than that in the $\mathrm{FT}+\mathrm{Na}_{2} \mathrm{SO}_{4}$ group, and the MDA content in the FT group was the lowest, indicating that the alfalfa seedlings were subjected to salt stress after the salt solution treatment. Research showed that plants responded to salinity in a two-stage response (Munns, 2005). The first stage was due to the osmotic pressure caused by the salt outside the 
plants, and the second stage was due to the toxic effect of the salt, which exceeded the ability of the cells to divide the salt in the vacuole. Salinity exacerbated cell membrane lipid peroxidation and accumulated more $\mathrm{MDA} . \mathrm{Cl}^{-}$and $\mathrm{SO}_{4}{ }^{2-}$ showed differences in plant stress, and the damage caused by $\mathrm{Cl}^{-}$was stronger than by $\mathrm{SO}_{4}{ }^{2-}$, probably because alfalfa had effective mechanisms to exclude $\mathrm{Na}$ and $\mathrm{S}$ and part $\mathrm{Cl}$ ions from leaves. The remaining not excluded $\mathrm{Cl}$ ions produced toxic effects, destroyed cell structure and inhibited plant growth. The decrease in growth may also be due to an increase in the metabolic cost of excluding, separating, or increasing the synthesis of the permeate, reducing the amount of organic compound available for growth (Lissner and Schierup, 1997; Mccree, 1986).

\section{Changes in antioxidant enzyme activity}

Salinity-induced increased antioxidant activity is associated with plant salt tolerance (Bose et al., 2014). It can be seen from Figures 5 and 6 that the trend of SOD and POD activity in the treated groups was consistent, and the change rule was first raised and then maintained at a higher level during the whole freeze-thaw cycle. As the temperature decreased, the SOD activity gradually increased, and the maximum value appeared at $\mathrm{T} 4\left(-3^{\circ} \mathrm{C}\right)$, then decreased slightly, but was still very high. POD activity increased first, and the maximum value appeared at $\mathrm{T} 4\left(-3^{\circ} \mathrm{C}\right)$, then the decrease was not obvious, and there was no significant difference between the groups $(P>0.05)$. The activity of SOD and POD increased significantly with temperature, indicating that membrane lipid peroxidation occurred in plants under low temperature and salt stress, and a large amount of superoxide anion radicals were produced. ROS was rapidly produced in plants in the form of $\mathrm{H}_{2} \mathrm{O}_{2}$ and $\mathrm{O}_{2}{ }^{-}$(Zang et al., 2015). The production of ROS led to the activation of programmed cell death, and the cells underwent various stages of apoptosis, such as externalization of phosphatidylserine, DNA laddering, loss of plasma membrane integrity (Swapnil et al., 2017). The stress resistance of plants induced the activity of SOD and POD. SOD could convert superoxide anion into $\mathrm{H}_{2} \mathrm{O}_{2}$, whereas POD could decompose $\mathrm{H}_{2} \mathrm{O}_{2}$ and synergize with SOD to scavenge reactive oxygen species in order to reduce cell membrane damage. In the late stage of freezethaw cycle (temperature rose phase), the plants were exposed to sustained low temperature, SOD and POD activity was still high, mainly because the long-term cold environment caused the active oxygen free radicals to continue to accumulate, although the temperature was in the recovery phase, plants were still severely stressed. SOD is an important component of the active oxygen scavenging system in plants (Zhu et al., 2007). When plants responded to external environmental stress, POD and SOD acted synergistically to protect the body from external stress, and the activity changes of the two were significantly correlated (Qi et al., 2003).

The three treated groups showed the strongest POD and SOD activity in the $\mathrm{FT}+\mathrm{NaCl}$ group, the second in the $\mathrm{FT}+\mathrm{Na}_{2} \mathrm{SO}_{4}$ group, and the weakest in the FT group, indicating that compound stress could lead to increased cell membrane lipid peroxidation, and different types of salt solutions had different effects on plant cells. Compared with $\mathrm{Na}^{+}$(Bhivare et al., 1988; Chavan and Karadge, 1980) and $\mathrm{SO}_{4}{ }^{2-}$, plants were more sensitive to $\mathrm{Cl}^{-}$, which may give rise to enhancement of cell membrane lipid peroxidation, and ROS was produced enough to increase the antioxidant activity of plants. In addition, studies (Cameron and Pakrasi, 2010) have shown that sulfate in cells could promote the synthesis of glutathione, which had been shown to be critical for many processes in plants and promoted plant growth. 


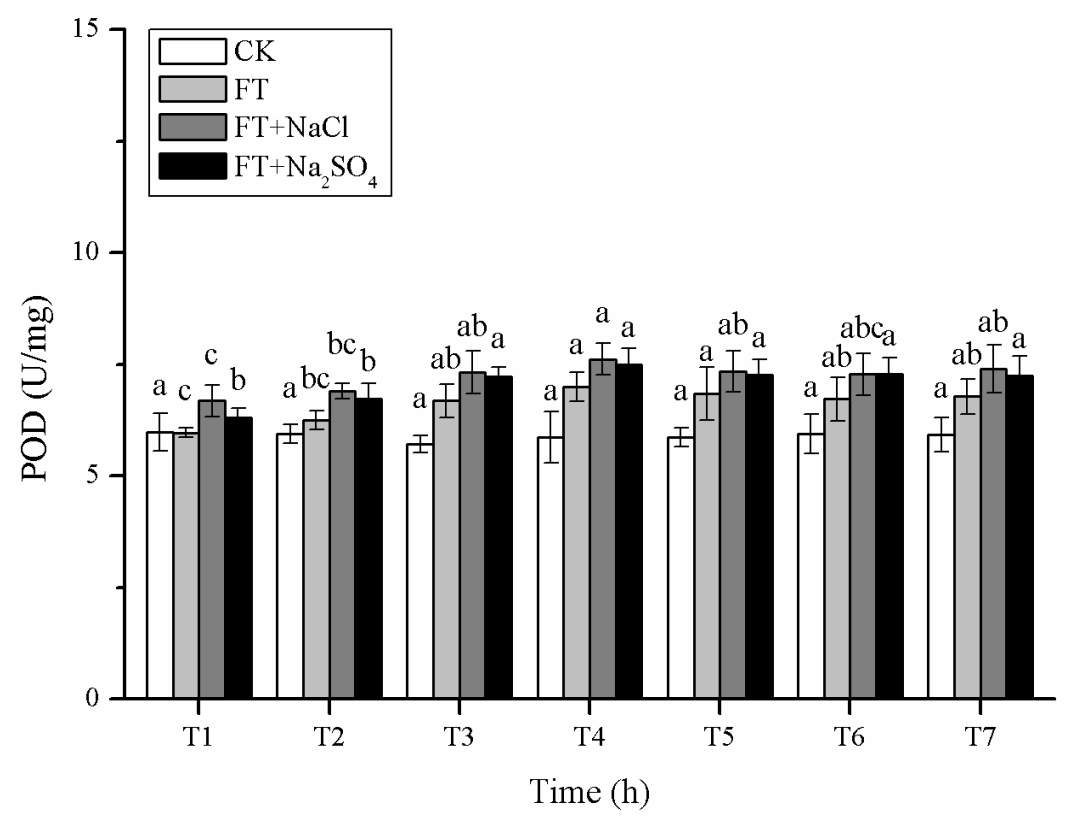

Figure 5. Effect of freezing-thawing cycle and two neutral salts on the content of POD

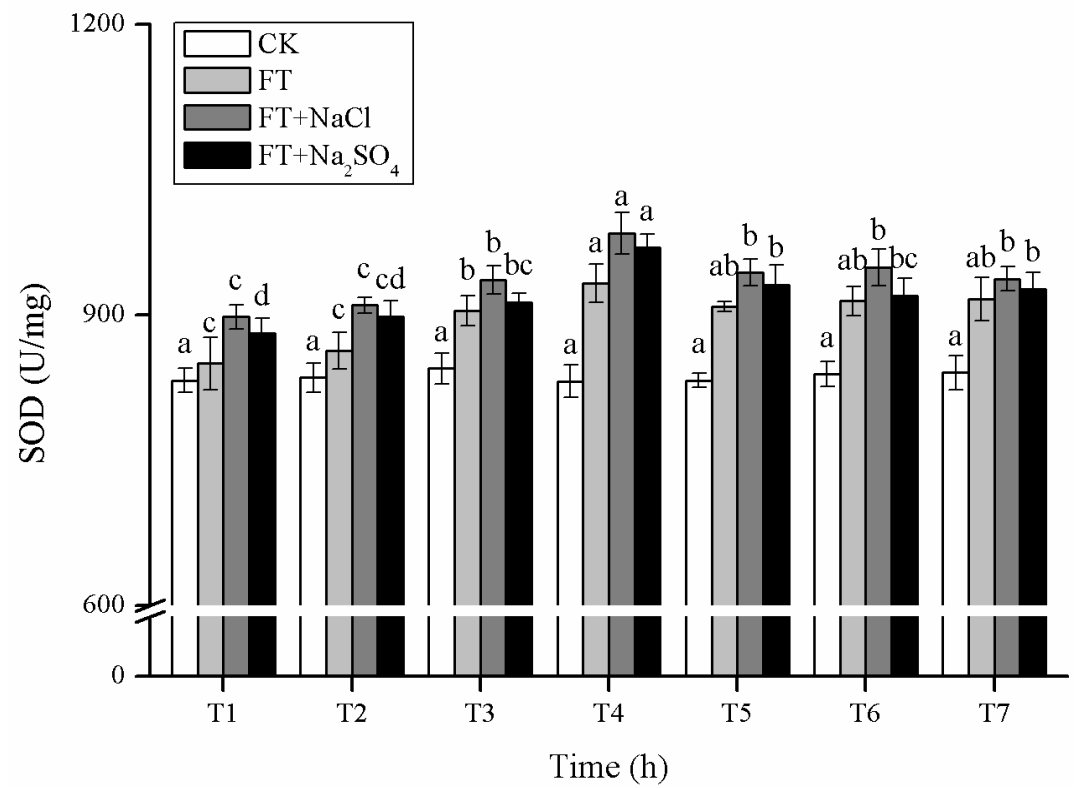

Figure 6. Effect of freezing-thawing cycle and two neutral salts on the content of SOD

\section{Conclusion}

Freeze-thaw cycles and salinity have a negative impact on the growth of alfalfa seedlings and have certain regularity, which could be proved by many related studies as well (Lissner and Schierup, 1997; Lissner et al., 1999; Matsushita and Matoh, 1991; Vasquez et al., 2006). Our research suggested that this might be due to temperature, penetration and ion specificity. Alfalfa showed certain tolerance to low temperature and salinity, which was characterized by overexpression of related genes to synthesize soluble protein, huge production of soluble sugar, proline and other solutes regulating 
osmotic potential, the accumulation of MDA by cell membrane lipid peroxidation, and the enhancement of antioxidant enzyme activity to scavenge ROS. In a freeze-thaw cycle, each indicator and temperature had a certain degree of negative correlation. Compared with single freeze-thaw stress, compound stress had stronger ability to inhibit plant growth, mainly due to the penetration and toxicity of salt ions. For different types of salinity, the plant response was different, showing pronounced ion specificity. Equimolar $\mathrm{NaCl}$ was more stressful than $\mathrm{Na}_{2} \mathrm{SO}_{4}$ on alfalfa seedlings, and the stress was mainly from the toxic effect of $\mathrm{Cl}^{-}$rather than $\mathrm{Na}^{+}$or $\mathrm{SO}_{4}{ }^{2-}$. This may be due to the fact that alfalfa was more sensitive to $\mathrm{Cl}^{-}$and had $\mathrm{Na}^{+}, \mathrm{SO}_{4}{ }^{2-}$ and partial $\mathrm{Cl}^{-}$efflux mechanisms. $\mathrm{Cl}^{-}$might affect a variety of important chemical actions in cells, and cells underwent normal metabolic activities, thereby inhibiting plant growth. It can provide a reference for scientific management of either farmland or lawn of alfalfa. However, whether the adaptation mechanisms of short-term stress were consistent with those of long-term one, it needs to be further investigated.

Acknowledgments. This work was supported by the [National Natural Science Foundation of China] under Grant [31772669].

Conflict of interests. The authors declare no conflict of interests.

\section{REFERENCES}

[1] Akandi, Z. N., Pirdashti, H., Yaghoubian, Y., Omran, V. G. (2017): Response of quantitative and physiological parameters of stevia (Stevia rebaudiana Bertoni) medicinal plant to salinity stress under controlled conditions. - Journal of Science and Technology of Greenhouse Culture 8(1): 9-20.

[2] Al-Khatib, M. M., McNeilly, T., Collins, J. C. (1994): Between and within cultivar variability in salt tolerance in lucerne (Medicago sativa L.). - Genetic Resources and Crop Evolution 41(3): 159-164.

[3] Bailly, C., Benamar, A., Corbineau, F., Come, D. (1996): Changes in malondialdehyde content and in superoxide dismutase, catalase and glutathione reductase activities in sunflower seeds as related to deterioration during accelerated aging. - Physiologia Plantarum 97(1).

[4] Bao, G. Z., Ao, Q., Li, Q. Q., Bao, Y. S., Zheng, Y., Feng, X. X., Ding, X. M. (2017): Physiological characteristics of Medicago sativa L. in response to acid deposition and freeze-thaw stress. - Water Air and Soil Pollution 228(9).

[5] Bhivare, V. N., Nimbalkar, J. D., Chavan, P. D. (1988): Photosynthetic carbon metabolism in French bean leaves under saline conditions. - Environmental \& Experimental Botany 28(2): 117-121.

[6] Bian, W. J., Bao, G. Z., Qian, H. M., Song, Z. W., Qi, Z. M., Zhang, M. Y., Chen, W. W., Dong, W. Y. (2018): Physiological response characteristics in Medicago sativa under freeze-thaw and deicing salt stress. - Water Air and Soil Pollution 229(6).

[7] Bose, J., Rodrigo-Moreno, A., Shabala, S. (2014): ROS homeostasis in halophytes in the context of salinity stress tolerance. - Journal of Experimental Botany 65(5): 1241-1257.

[8] Briens, M., Larher, F. (2010): Osmoregulation in halophytic higher plants: a comparative study of soluble carbohydrates, polyols, betaines and free proline. - Plant Cell \& Environment 5(4): 287-292.

[9] Cameron, J. C., Pakrasi, H. B. (2010): Essential role of glutathione in acclimation to environmental and redox perturbations in the Cyanobacterium Synechocystis sp. PCC 6803. - Plant Physiology 154(4): 1672-1685. 
[10] Chavan, P. D., Karadge, B. A. (1980): Influence of sodium chloride and sodium sulfate salinities on photosynthetic carbon assimilation in peanut. - Plant and Soil 56(2): 201207.

[11] Deng, X., Qiao, D., Li, L., Yu, X., Zhang, N., Lei, G., Cao, Y. (2005): Effect of low temperature stress on physiological characteristics of alfalfa. - Journal of Sichuan University (Natural Science Edition): 42(1): 190-194.

[12] Flowers, T. J. (2004): Improving crop salt tolerance. - Journal of Experimental Botany 55(396): 307-319.

[13] Greenway, H., Munns, R. (2003): Mechanisms of salt tolerance in nonhalophytes. Annual Review of Phytopathology 31(4): 149-190.

[14] Guy, C. L. (1990): Cold acclimation and freezing stress tolerance: role of protein metabolism. - Annual Review of Plant Physiology and Plant Molecular Biology 41: 187223.

[15] Hannah, M. A., Heyer, A. G., Hincha, D. K. (2005): A global survey of gene regulation during cold acclimation in Arabidopsis thaliana. - Plos Genetics 1(2): 179-196.

[16] Hu, Y. C., Schmidhalter, U. (2005): Drought and salinity: a comparison of their effects on mineral nutrition of plants. - Journal of Plant Nutrition and Soil Science 168(4): 541-549.

[17] James, R. A., Rivelli, A. R., Munns, R., von Caemmerer, S. (2002): Factors affecting $\mathrm{CO} 2$ assimilation, leaf injury and growth in salt-stressed durum wheat. - Functional Plant Biology 29(12): 1393-1403.

[18] Kanmani, E., Ravichandran, V., Sivakumar, R., Alagarswamy, S., Krishna Surendar, K., Parasuraman, B. (2017): Influence of plant growth regulators on physiological traits under salinity stress in contrasting rice varieties (Oryza sativa L.). - International Journal of Current Microbiology and Applied Sciences 6: 1654-1661.

[19] Lissner, J., Schierup, H.-H. (1997): Effects of salinity on the growth of Phragmites australis. - Aquatic Botany 55(4).

[20] Lissner, J., Schierup, H. H., Comin, F. A., Astorga, V. (1999): Effect of climate on the salt tolerance of two Phragmites australis populations. I. Growth, inorganic solutes, nitrogen relations and osmoregulation. - Aquatic Botany 64(3-4): 317-333.

[21] Hahn, M., Walbot, V. (1989): Effects of cold-treatment on protein synthesis and mRNA levels in rice leaves. - Plant Physiology 91(3).

[22] Matoh, T., Matsushita, N. (2010): Salt tolerance of the reed plant Phragmites communis [halophytes]. - Physiologia Plantarum 72(1): 8-14.

[23] Matsushita, N., Matoh, T. (1991): Characterization of Na+ exclusion mechanisms of salttolerant reed plants in comparison with salt-sensitive rice plants. - Physiologia Plantarum 83(1): 170-176.

[24] McCoy, T. J. (1987): Tissue culture evaluation of $\mathrm{NaCl}$ tolerance in Medicago species: cellular versus whole plant response. - Plant Cell Reports 6(1).

[25] Mccree, K. J. (1986): Whole-plant carbon balance during osmotic adjustment to drought and salinity stress. - Functional Plant Biology 13(1): 33-43.

[26] Munns, R. (2005): Genes and salt tolerance: bringing them together. - New Phytologist 167(3): 645-663.

[27] Nguyen, H., Polanco, M. C., Zwiazek, J. J. (2006): Gas exchange and growth responses of ectomycorrhizal Picea mariana, Picea glauca, and Pinus banksiana seedlings to $\mathrm{NaCl}$ and Na2SO4. - Plant Biology 8(5): 646-652.

[28] Pagter, M., Bragato, C., Malagoli, M., Brix, H. (2009): Osmotic and ionic effects of $\mathrm{NaCl}$ and Na2SO4 salinity on Phragmites australis. - Aquatic Botany 90(1): 43-51.

[29] Pompeiano, A., Di Patrizio, E., Volterrani, M., Scartazza, A., Guglielminetti, L. (2016): Growth responses and physiological traits of seashore paspalum subjected to short-term salinity stress and recovery. - Agricultural Water Management 163: 57-65.

[30] Qi, D., Li, X., Wang, L., Deng, X., Yang, Y., Liu, Y. (2003): Effects of simulated low temperature stress on the protective enzyme system of reactive oxygen species - a case 
study of Podocarpus fleuryi Hickel seedlings. - Journal of Southwest University (Natural Science Edition): 25(5): 385-388.

[31] Renault, S., Croser, C., Franklin, J. A., Zwiazek, J. J. (2001): Effects of $\mathrm{NaCl}$ and $\mathrm{Na} 2 \mathrm{SO} 4$ on red-osier dogwood (Cornus stolonifera Michx) seedlings. - Plant and Soil 233(2): 261-268.

[32] Rogers, M. E., Grieve, C. M., Shannon, M. C. (1998): The response of lucerne (Medicago sativa L.) to sodium sulphate and chloride salinity. - Plant and Soil 202(2): 271-280.

[33] Seppänen, M. M., Majaharju, M., Somersalo, S., Pehu, E. (1998): Freezing tolerance, cold acclimation and oxidative stress in potato. Paraquat tolerance is related to acclimation but is a poor indicator of freezing tolerance. - Physiologia Plantarum 102(3).

[34] Skinner, D. Z., Bellinger, S. B., Hansen, C. J., Kennedy, C. A. (2014): Carbohydrate and lipid dynamics in wheat crown tissue in response to mild freeze-thaw treatments. - Crop Science 54(4).

[35] Skinner, D. Z., Bellinger, B. S. (2017): Freezing tolerance of winter wheat as influenced by extended growth at low temperatures and exposure to freeze-thaw cycles. - Canadian Journal of Plant Science 97(2): 250-256.

[36] Stushnoff, C., Junttila, O. (1986): Seasonal development of cold stress resistance in several plant species at a coastal and a continental location in North Norway. - Polar Biology 5(3): 129-133.

[37] Swapnil, P., Yadav, A. K., Srivastav, S., Sharma, N. K., Srikrishna, S., Rai, A. K. (2017): Biphasic ROS accumulation and programmed cell death in a cyanobacterium exposed to salinity ( $\mathrm{NaCl}$ and Na2SO4). - Algal Research 23: 88-95.

[38] Türkan, I., Demiral, T. (2009): Recent developments in understanding salinity tolerance. - Environmental and Experimental Botany 67(1).

[39] Vasquez, E. A., Glenn, E. P., Guntenspergen, G. R., Brown, J. J., Nelson, S. G. (2006): Salt tolerance and osmotic adjustment of Spartina alterniflora (Poaceae) and the invasive M haplotype of Phragmites australis (Poaceae) along a salinity gradient. - American Journal of Botany 93(12): 1784-1790.

[40] Volkmar, K. M., Hu, Y., Steppuhn, H. (1998): Physiological responses of plants to salinity: a review. - Canadian Journal of Plant Science 78(1): 19-27.

[41] Weiser, C. J. (1970): Cold resistance and injury in woody plants. - Science 169(3952): 1269-1278.

[42] Zang, D., Wang, C., Ji, X., Wang, Y. (2015): Tamarix hispida zinc finger protein ThZFP1 participates in salt and osmotic stress tolerance by increasing proline content and SOD and POD activities. - Plant Science 235: 111-121.

[43] Zhu, H., Sun, W., Deng, B., Yan, N., Wu, J., Fan, H., Ye, J., Zeng, J., Liu, Y., Zhang, Y. (2007): Study on cold hardiness and its physiological and biochemical characteristics of winter turnip rape (Brassica campetris). - Northwest Agricultural Journal 16(4): 34-38. 